University of Nebraska - Lincoln

DigitalCommons@University of Nebraska - Lincoln

\title{
Aerosol delivery of trail pheromone disrupts the foraging of the red imported fire ant, Solenopsis invicta
}

\author{
David Maxwell Suckling \\ The New Zealand Institute for Plant and Food Research, max.suckling@plantandfood.co.nz \\ Lloyd D. Stringer \\ The New Zealand Institute for Plant and Food Research \\ Joshua E. Corn \\ The New Zealand Institute for Plant and Food Research \\ Barry Bunn \\ The New Zealand Institute for Plant and Food Research \\ Ashraf M. El-Sayed \\ The New Zealand Institute for Plant and Food Research \\ See next page for additional authors
}

Follow this and additional works at: https://digitalcommons.unl.edu/usdaarsfacpub

Suckling, David Maxwell; Stringer, Lloyd D.; Corn, Joshua E.; Bunn, Barry; El-Sayed, Ashraf M.; and Vander Meer, Robert K., "Aerosol delivery of trail pheromone disrupts the foraging of the red imported fire ant, Solenopsis invicta" (2012). Publications from USDA-ARS / UNL Faculty. 1126.

https://digitalcommons.unl.edu/usdaarsfacpub/1126

This Article is brought to you for free and open access by the U.S. Department of Agriculture: Agricultural Research Service, Lincoln, Nebraska at DigitalCommons@University of Nebraska - Lincoln. It has been accepted for inclusion in Publications from USDA-ARS / UNL Faculty by an authorized administrator of DigitalCommons@University of Nebraska - Lincoln. 


\section{Authors}

David Maxwell Suckling, Lloyd D. Stringer, Joshua E. Corn, Barry Bunn, Ashraf M. El-Sayed, and Robert K. Vander Meer 


\title{
Aerosol delivery of trail pheromone disrupts the foraging of the red imported fire ant, Solenopsis invicta
}

\author{
David Maxwell Suckling, ${ }^{\text {a* }}$ Lloyd D Stringer, $^{\mathrm{a}}$ Joshua E Corn, $^{\mathrm{a}}$ Barry Bunn, ${ }^{\mathrm{b}}$ \\ Ashraf M El-Sayed ${ }^{\mathrm{a}}$ and Robert K Vander Meerc
}

\begin{abstract}
BACKGROUND: The fire ant, Solenopsis invicta, is one of the most aggressive and invasive species in the world. The trail pheromone $Z, E-\alpha$-farnesene ( $91 \%$ purity) was prepared, and disruption of worker trail orientation was tested using an ethanolbased aerosol formulation presenting a single puff of this compound by airbrush and compressed air. Trail-following behaviour was recorded by overhead webcam and ants digitised before and after presentation of the aerosol treatment at four rates (1.6, 16,160 and $1600 \mathrm{ng} \mathrm{cm}^{-2}$ ).
\end{abstract}

RESULTS: Ants preferred $110 \mathrm{ng} \mathrm{cm}^{-1}$ over 11, 1.1 and $0.11 \mathrm{ng} \mathrm{cm}^{-1}$ for trail following. Within seconds of presentation of $1600 \mathrm{ng} \mathrm{cm}^{-2}$, the highest dose tested, trail disruption was observed. Disruption was evident as reduced arrival success and reduction in the trail integrity statistic $\left(r^{2}\right)$, as well as increased deviation from the trail (deg). The distribution of walking track angles was also flattened.

CONCLUSIONS: The feasibility of using aerosol for delivery of trail pheromone was demonstrated, but the need for high purity combined with the difficulty of commercial supply makes this technique impractical. However, the commercial production of $Z, E-\alpha$-farnesene of high purity by industrial biotechnology or from (E)-nerolidol may be possible in future, which would facilitate further development of trail pheromone disruption of S. invicta.

(c) 2012 Society of Chemical Industry

Keywords: red imported fire ant; ant; trail pheromone; trail disruption; invasive species; $Z, E$ - $\alpha$-farnesene; Solenopsis invicta; pheromone delivery

\section{INTRODUCTION}

Many invasive ants are expanding their geographic range and level of impacts. Of these pests, Solenopsis invicta (red imported fire ant) is arguably the most serious because of a range of effects on wildlife ${ }^{1}$ and agriculture, interruption of biological control in production ecosystems ${ }^{2}$ and medical effects on people. ${ }^{3}$ Although the fire ant recruitment, alarm and queen recognition pheromone systems have been at least partly elucidated over the last few decades, ${ }^{4,5}$ their application in fire ant control has been elusive, and the pest control paradigm for ants remains largely confined to improving the performance of toxic baits, ${ }^{6}$ as toxic baits normally require the use of large amounts of insecticide. ${ }^{7}$ New strategies, including application technologies that deliver pheromones against invasive pest ants, could help to reduce the reliance on the use of insecticides for fire ants and other invasive pest ants, especially in sensitive ecosystems or where classical toxic baits are otherwise undesirable. Fire ant trail pheromone disruption could affect recruitment to food resources and provide a novel control tactic to add to the current integrated pest management toolbox. ${ }^{8}$ Some progress using this approach has been made against the invasive Argentine ant. ${ }^{9-13}$

The recruitment process of S. invicta is complicated, involving the defined recruitment behaviours of attraction, orientation induction and orientation. The recruitment pheromone is produced by the Dufours gland located in the worker abdomen and attached to the base of the sting apparatus. ${ }^{14}$ After a foraging worker ant finds a food source that is too big to retrieve, it will deposit recruitment pheromone back to the nest, where workers are recruited and motivated to follow the trail to the food source. ${ }^{15}$ Attraction and orientation induction have a lowest active concentration 100 times that of the ants' sensitivity to orientation - movement back and forth along the trail. $Z, E-\alpha$-farnesene was found to be solely responsible for the orientation component of the recruitment pheromone. The other behaviours require more than one component. The single component and the high

\footnotetext{
* Correspondence to: David Maxwell Suckling, The New Zealand Institute for Plant and Food Research, PB 4704, Christchurch 8140, New Zealand.

E-mail:max.suckling@plantandfood.co.nz

a The New Zealand Institute for Plant and Food Research,Christchurch, New Zealand

b The New Zealand Institute for Plant and Food Research, Palmerston North, New Zealand

c USDA ARS, Gainesville, FL, USA
} 
sensitivity of the workers to $Z, E-\alpha$-farnesene make it a logical target for experiments in trail pheromone disruption. ${ }^{16}$ Preliminary results showed that an established fire ant trail in the laboratory could be disrupted using larger than physiologically natural amounts of $Z, E-\alpha$-farnesene applied to a filter paper substrate. ${ }^{17}$ However, practical application needs a different delivery system. Sustained-release formulations or mechanical methods of dispensing appropriate amounts of the orientation pheromone offer promising solutions to the pheromone delivery problem.

A novel pheromone-dispensing system has been developed for use against moths in a range of indoor and outdoor environments, offering considerable flexibility in delivery to match the needs of particular pests. It uses periodically activated pressurised cans to release pheromone into the air. ${ }^{18-22}$ Apart from providing the potential to improve the timing of pheromone applications to target insect activity better, the aerosol cans also protect formulations from degradation by oxidation or UV light, which would be beneficial for the utilisation of $Z, E-\alpha$-farnesene. This is the first report of aerosols as an orientation pheromone delivery system for disruption of fire ant recruitment.

\section{EXPERIMENTAL METHODS}

\subsection{Insects}

Five polygyne queen-right ant colonies were established and maintained ${ }^{23}$ in Florida. Colonies had water access, but no food was available for at least $24 \mathrm{~h}$ prior to the start of experiments to encourage foraging.

\subsection{Chemicals and synthesis}

The preparation of $E, E-\alpha$-farnesene from $60 \mathrm{~kg}$ of $\mathrm{cv}$. Granny Smith apples (Malus domestica $\times$ M. sylvestris) was done following Murray. ${ }^{24}$ The product was collected as colourless oil, ${ }^{25}$ yielding $1.05 \mathrm{~g}$ of $E, E-\alpha$-farnesene. To obtain $Z, E-\alpha$-farnesene, $E, E-\alpha-$ farnesene was photoisomerised following Ramaiah et al. ${ }^{26}$ as described earlier. ${ }^{16}$ The product obtained was a mixture of $Z, E: E, E$ isomers in the proportion $91: 9$, as determined by gas chomatography-mass spectrometry. The yield was $115 \mathrm{mg}$. The $Z, E-\alpha$-farnesene was diluted in ethanol for use. Three other unknown compounds were also present in the solution at approximate concentrations of 4,6 and $7 \%$ of the mixture (possibly including the other two isomers $E, Z$ and $Z, Z$; these compounds have activity, but orders of magnitude less than that of the $Z, E$-isomer). ${ }^{16}$

\subsection{Experiment 1: trail establishment}

It was hypothesised that preferred concentrations required for trailing would be chosen and demonstrated by a sample of 30 walking ants, presented with four radiating options with different concentrations upon arrival. Because concentration-dependent insect behaviour was demonstrated unequivocally in the assay, the experiment was replicated only 4 times, with the order rotated, ensuring one test with each position. The trail recording approach reported by Suckling et al. ${ }^{12,27}$ was used, with an isolated horizontal glass plate $(500 \times 200 \times 5 \mathrm{~mm})$ as the substrate, connected by a single wire at one diagonal end to channel and regulate the foraging of an ant between nest and food source. A white background, with faint pencil lines drawn on paper under the glass, was used to maximise contrast. Trails were filmed overhead (i.e. at $90^{\circ}$ ) using a webcam (Logitech Pro 9000; Logitech, Freemont, CA; screen size $80 \%$ of actual size, $960 \times 720$ pixels at 15 frames $\mathrm{s}^{-1}$ ).
This allowed viewing of the maximum length of the trail on the glass and the determination of trail integrity (defined as a significant value of $r^{2}$ ) of the base trail. The trails $(20 \mathrm{~cm}$ length) of $Z, E-\alpha$-farnesene were applied at four rates on a log scale (110, $11,1.1$ and $0.11 \mathrm{ng} \mathrm{cm}^{-1}$ ) by streaking $2.25 \mu \mathrm{L}$ of pheromone in $70 \%$ ethanol, from a glass capillary tube, in a straight line, with the four trails radiating at $25^{\circ}$ from a start point connected to a colony. Four replicates were run, with the position of trails varying for each treatment. Low-speed directional air movement $\left(\sim 0.05 \mathrm{~m} \mathrm{~s}^{-1}\right)$ was generated by conducting the experiment $1.5 \mathrm{~m}$ from a fume hood. Experiments were conducted for a minimum of 30 ants per treatment. A dental roll with $10 \%$ sugar water was placed at the end of each trail downwind to provide a reward and to assess the success of forager ants in discovering this food source, as well as reducing the incidence of ants walking back onto the glass sheet, depositing natural trail compounds. Only ants leaving the nest were recorded. This was done to reduce the influence of any additional cues to the trail pheromone that returning ants may have used to return to the nest. Thus, continuous analyses of ants walking (up to 25 frame $^{-1}$ ) were conducted after file processing using novel software developed in house with the HALCON/C language interface (2009; MvTech Software GmbH, Munich, Germany) for the Microsoft Windows operating system. The digitised images, recorded per frame as $X, Y$ coordinates for each insect, were stored as a text file. Images of the tracks were created using the graphing software Origin v.8.5 in order to visualise the density of ants trailing on each trail, and counts of the ants trailing on each trail were conducted for the first 30 ants of each treatment from recorded movies, with ants assigned to one of the four. Ants were assigned to a trail if they met the requirements of both following a minimum of $50 \mathrm{~mm}$ of a trail and reaching the destination via the corresponding trail for the final length of the journey. Ambiguous results where no trail could be assigned were excluded.

\subsection{Experiment 2: pheromone delivery by aerosol}

A $24 \mathrm{~cm}$ long trail of the trail pheromone $Z, E-\alpha$-farnesene was laid following the procedure in Suckling et al. ${ }^{27}$ at a concentration of $93.6 \mathrm{ng} \mathrm{cm}^{-1}$ with a glass plate $(500 \times 200 \times 5 \mathrm{~mm})$ as the substrate, with a pencilled line on paper underneath to indicate the trail. A colony of the red imported fire ant, Solenopsis invicta, was connected to the trail via a wire bridge. Trailing was filmed overhead using a webcam (1280 by 720 pixels). Trailing of the ants was established with a minimum of ten ants passing along the trail between the colony and a dental roll (containing 10\% sugar water) at the opposite end of the trail, to determine the baseline behaviour prior to treatments. An experimental aerosol delivery system was used to deploy the trail pheromone $Z, E-\alpha$-farnesene at four concentrations $\left(1.6,16,160\right.$ and $\left.1600 \mathrm{ng} \mathrm{cm}^{-2}\right)$ and a $70 \%$ ethanol control into the centre of the trail area, following an initial period of several minutes of continuous trail formation. The aerosol delivery system comprised a single-action bottom-feed airbrush driven by compressed air (124 kPa) (Badger 200; Badger Airbrush Co., Franklin Park, IL). The dosage was precisely controlled using a small solonoid with electronic timer microswitch control plumbed in the air line, with teflon tubing for the liquid feed. The ethanol-based aerosol was operated for $0.5 \mathrm{~s}$ for each single puff, after priming. The aerosol was mounted pointing orthogonally down $\left(67^{\circ}\right.$ from vertical) at the straight trail in the centre of the glass table, at a distance of $0.8 \mathrm{~m}$ and a height of $30 \mathrm{~cm}$.

The concentration of $Z, E-\alpha$-farnesene released from a single puff by the delivery system onto the glass treatment area was 
determined from calibration experiments. This involved capture of the material on five glass cover slips $(22 \times 22 \mathrm{~mm})$, which were rinsed twice with $1 \mathrm{~mL}$ of $n$-hexane on each occasion. To the resulting solution, $50 \mu \mathrm{L}$ of $\mathrm{C} 16$ was added as internal standard for subsequent quantification by gas chromatography-mass spectrometry.

Analysis of trails commenced after a minimum of 450 frames (30 s) following the spray, and only ants entering the start of the trail in the lower left corner of the recorded frame were analysed, with ants spending less than 75 frames in the field of view excluded. Walking of individual ants was analysed using MaxTraq v.1.9 (Innovision Systems, Lapeer, MI).

\subsection{Analysis}

Five trail-following statistics were recorded, in order better to understand how different statistics perform in assessing trail pheromone disruption. They were: arrival success; the trail integrity $r^{2}$ stastistic; the mean distance from the trail; the walking track angle; the deviation from the trail (deg). Arrival success was recorded for each individual ant as binary data, with a positive result requiring ants to enter the screen in the bottom right 250 by 250 pixels (approximately 7\% of the total recorded area) and exit in the top right 250 by 250 pixels. The trail integrity statistic $\left(r^{2}\right)$ was calculated from the distribution of coordinates, as previously described. ${ }^{11}$ The average distance of each ant from the artificially laid trail was calculated from the perpendicular distance of each digitised ant coordinate $(X, Y)$ to the trail using the formula Distance $=\left|(B \times X-Y+C) / \sqrt{ }\left(B^{2}-1\right)\right|$, where $B$ is the gradient and $C$ is the intercept of the line made by the trail, calculated by digitising the start and end points of the trail and determining the line between the two points (Fig. 1). The walking track angles of ants were analysed using sequential frames and calculated as $\theta^{\circ}=\arctan \Delta X / \Delta Y \times 180 / \pi$, where $\theta^{\circ}$ is the walking angle and $\Delta X$ and $\Delta Y$ are the distance travelled between two consecutive frames on the $X-Y$ axis. The deviation of consecutive points from the trail (deg) was calculated using dot products between two vectors, with one vector passing through two consecutive digitised points, $p_{1}=\left(x_{1}, y_{1}\right)$ and $p_{2}=\left(x_{2}, y_{2}\right)$, and the second vector representing the trail passing through two digitised points $p_{\mathrm{t} 1}=\left(x_{\mathrm{t} 1}, y_{\mathrm{t} 1}\right)$ and $p_{\mathrm{t} 2}=\left(x_{\mathrm{t} 2}, y_{\mathrm{t} 2}\right)$, at the start and end of the synthetic pheromone trail respectively. The dot products used were $\Delta X, \Delta Y, \Delta X_{\mathrm{t}}$ and $\Delta Y_{\mathrm{t}}$, with $\Delta X$ and $\Delta Y$ representing the distance between points $p_{1}$ and $p_{2}$ on the $X-Y$ axis, and $\Delta X_{t}$ and $\Delta Y_{\mathrm{t}}$ representing the distance between points $p_{\mathrm{t} 1}$ and $p_{\mathrm{t} 2}$ on the $X-Y$ axis. The deviation from the trail was calculated from these dot products as: $d=\left\{\operatorname{arcos}\left[\left(\Delta X \times \Delta X_{\mathrm{t}}\right)+\left(\Delta Y \times \Delta Y_{\mathrm{t}}\right)\right] /\left[\sqrt{ }\left(\Delta X^{2}+\right.\right.\right.$ $\left.\left.\left.\Delta Y^{2}\right)\right] \times\left[\sqrt{ }\left(\Delta X_{t}^{2}+\Delta Y_{t}^{2}\right)\right]\right\} \times 180 / \pi$, the result of which yields all positive angles (deg). These angles were separated as either positive or negative according to whether the point $p_{2}$ lay above or below the trail. Points below the trail occur when $y_{2}$ is less than $B \times x_{2}+C$, where $B$ is the gradient and $C$ is the intercept of the line representing the trail through points $p_{\mathrm{t} 1}$ and $p_{\mathrm{t} 2}$, in which case the resulting angles were multiplied by -1 to give a distribution of angles between -180 and $180^{\circ}$.

A general linear model was conducted on the effect of $Z, E-\alpha$ farnesene released by the aerosol spray on residual error sums of squares, based on the method described in Suckling et al. ${ }^{27}$ The residual error sums of squares are, in effect, a distance measure in one dimension, as they are calculated from the vertical distance from the line to the point and not the perpendicular distance. A log transformation of the residual error sums of squares was used to meet the assumptions of normal distribution and homogeneity

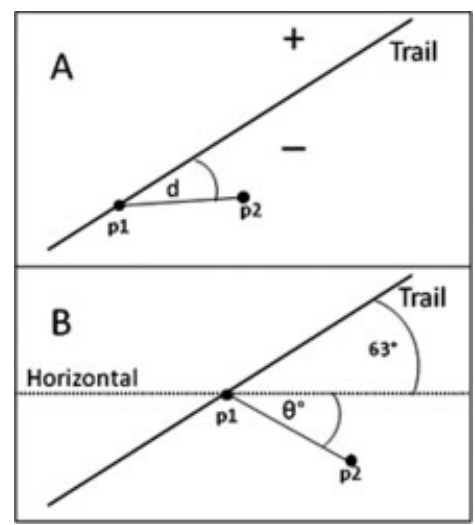

Figure 1. Method for calculating $(A)$ the deviation from the trail $(d)$ and (B) the walking track angle $(\theta)$.

of variance of the general linear model. A second analysis was conducted, with the colony added as a repeated factor, to examine for any effect on disruption measures. Ant arrival success was recorded in binary (success or failure), but the data were not analysed as replicates owing to an unbalanced design resulting from the lack of ants recorded in the higher concentrations (owing to disruption). Instead, the data were pooled and the percentage arrival was calculated.

\section{RESULTS}

\subsection{Experiment 1: trail establishment}

Preference for trails at the $Z, E-\alpha$-farnesene concentration of $110 \mathrm{ng} \mathrm{cm}^{-1}$ was evident, with the percentage of 30 ants on $110,11,1.1$ and $0.11 \mathrm{ng} \mathrm{cm}^{-1}$ trails at $65.0,28.3,4.2$ and $2.5 \%$ respectively. Greatest ant density was evident on the 110 and $11 \mathrm{ng} \mathrm{cm}^{-1}$ trails, irrespective of trail position (Fig. 2). Ants showed a preference for the $110 \mathrm{ng} \mathrm{cm}^{-1}$ trail in three out of four tests, with a preference for the $11 \mathrm{ng} \mathrm{cm}^{-1}$ trail on one occasion. Ants mostly followed trails in the range $11-110 \mathrm{ng} \mathrm{cm}^{-1}$. Fewer than $7 \%$ of the 120 recorded ants trailed on either 1.1 or $0.11 \mathrm{ng} \mathrm{cm}^{-1}$ trails.

\subsection{Experiment 2: pheromone delivery by aerosol}

A decrease in both arrival success and trail integrity $r^{2}$ statistic was achieved at $Z, E-\alpha$-farnesene concentrations above $160 \mathrm{ng} \mathrm{cm}^{-2}$, with $r^{2}$ dropping to almost 0.30 with an arrival success of $35 \%$ at $1600 \mathrm{ng} \mathrm{cm}^{-2}$ (Fig. 3). The mean distance from the trail also dropped above $160 \mathrm{ng} \mathrm{cm}^{-2}$, reaching a mean distance of $15 \mathrm{~mm}$ at $1600 \mathrm{ng} \mathrm{cm}^{-2}$ compared with less than $2 \mathrm{~mm}$ for 1.6 and $16 \mathrm{ng} \mathrm{cm}^{-2}$ aerosol spray applications.

A peak in walking track angles around the trail angle $\left(63^{\circ}\right)$ was observed at the lower $Z, E$ - $\alpha$-farnesene concentrations of 1.6 and $16 \mathrm{ng} \mathrm{cm}^{-2}$, with no evidence of effect from the aerosol spray. This peak flattened when trail pheromone was introduced at rates of $160 \mathrm{ng} \mathrm{cm}^{-2}$ and above (Fig. 4).

A similar pattern was observed for the deviation from the trail (Fig. 5), with an increase in frequency of angles further from the trail at a $Z, E-\alpha$-farnesene concentration of $160 \mathrm{ng} \mathrm{cm}^{-2}$ and above resulting in a flattening of the curve. At $1600 \mathrm{ng} \mathrm{cm}^{-2}$ an excess of ants above the trail line means more positive angles were recorded, which was likely an artefact due to wind direction towards the fume hood. There was a linear relationship between the trail integrity statistic $r^{2}$ and the deviation from the trail (Fig. 6). 


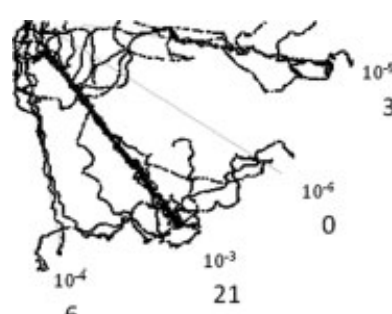

6

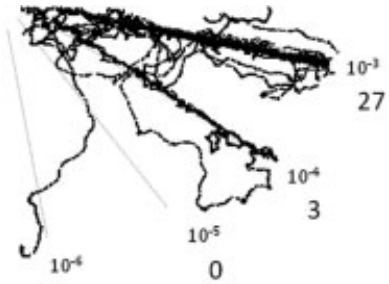

0

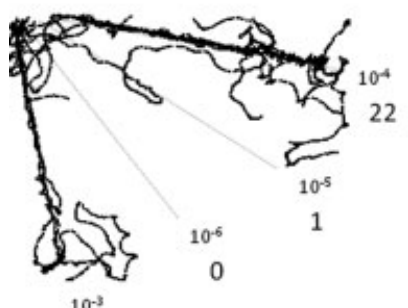

7

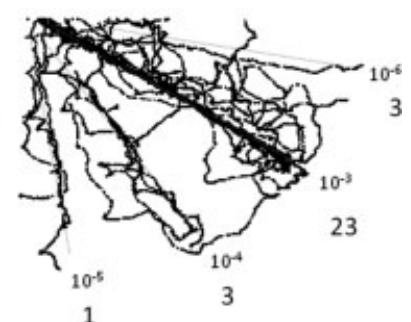

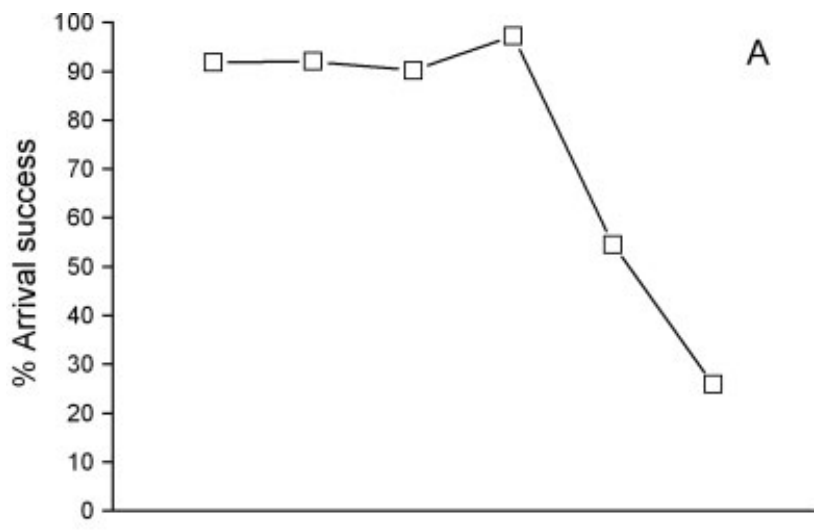

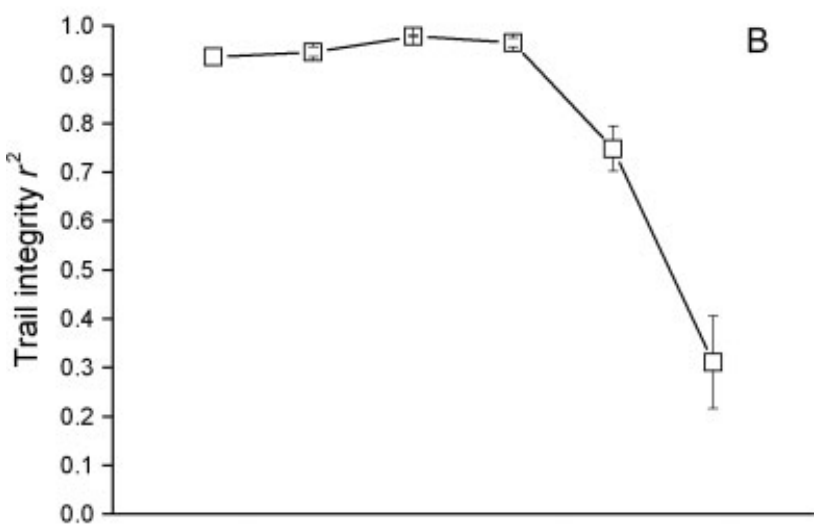

Figure 2. Four-way choice test for $Z, E$ - $\alpha$-farnesene trail strength in the red imported fire ant, Solenopsis invicta, repeated in different presentation order, with concentrations over four orders of magnitude $\left(10^{-3}=110 \mathrm{ng} \mathrm{cm}^{-1}\right)$.

The general linear model on residual error sums of squares showed the concentration of $Z, E-\alpha$-farnesene to have a significant effect on trailing $\left(F_{3}=5.76, P=0.01\right)$. Colony showed no significant effect and was excluded from the model. The analysis was an unbalanced design owing to a lack of ants in the $1600 \mathrm{ng} \mathrm{cm}^{-2}$ treatment, as this treatment had a repellant effect causing ants either not to enter the recorded area or to depart from the treatment area before sufficient frames could be captured. Treatments with fewer than five ants meeting the requirements were discarded.

\section{DISCUSSION}

Application of $Z, E-\alpha$-farnesene using the capillary method for trail establishment induced trailing of worker ants along the synthetic trails. The choice assay showed a preference for a trail concentration of $110 \mathrm{ng} \mathrm{cm}^{-1}$, with trailing also occurring down to $11 \mathrm{ng} \mathrm{cm}^{-1}$. This is much higher than the concentration for trail following in other species such as Linepithema humile $\left(1-100 \mathrm{pg} \mathrm{cm}^{-1}\right),{ }^{27}$ Atta sexdens sexdens $\left(15-150 \mathrm{pg} \mathrm{cm}^{-1}\right)^{28}$ and Myrmica rubra $\left(3-300 \mathrm{pg} \mathrm{cm}^{-1}\right) .{ }^{29}$ This suggests that the synthetic $Z, E$ - $\alpha$-farnesene used has an activity $\sim 1000$-fold lower than for other species described. It seems likely that the low (91\%) purity of the present $Z, E-\alpha$-farnesene played a key role in the apparent low activity observed. The natural product from $S$. invicta has a purity of $98 \%$, with $2 \% E, E-\alpha$-farnesene. ${ }^{16}$ The preferred $Z, E$-concentration is likely to be more concentrated than the natural trail, especially early in the recruitment process, ${ }^{30}$ and thus the amount needed to disrupt natural trails is likely to be less than reported here, although this hypothesis has not been tested. An off-ratio pheromone blend may not be as efficacious at disruption as the natural ratio, as has been observed in some moths. ${ }^{31,32}$ However, the absence from the present trails of other pheromones that elicit trailing behaviour in fire ants ${ }^{17}$ may also contribute to the large amount of $Z, E-\alpha$-farnesene required for disruption here. The quantity of $Z, E-$ $\alpha$-farnesene required for sufficient disruption during the aerosol experiment was estimated at $1600 \mathrm{ng} \mathrm{cm}^{-2}$. Again, this was a value much higher than found for other ants, e.g. Linepithema humile, ${ }^{27}$

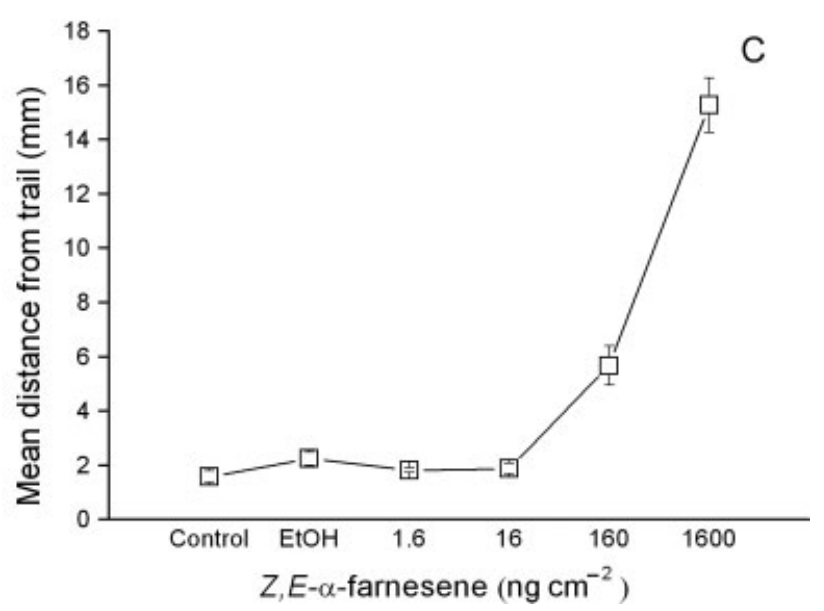

Figure 3. Effect of aerosol pheromone spray on trailing behaviour in the red imported fire ant, Solenopsis invicta, measured as: A, percentage arrival success; $B$, trail integrity $r^{2} ; C$, mean distance from trail.

where disruption of high concentration trails $\left(100 \mathrm{pg} \mathrm{cm}^{-1}\right)$ was achieved with a trail pheromone concentration of $100 \mathrm{ng} \mathrm{cm}^{-1}$ from a point source $10 \mathrm{~cm}$ long and running parallel to the trail at a distance of $1.5 \mathrm{~cm}$ (1000 ng total of material). This may be due to the lower purity of the present product, or to missing additional compounds with behavioural function in this complex system. Field experiments are needed to determine whether the natural trails can be disrupted with lower concentrations of $Z$, E- $\alpha$-farnesene.

Because there has been limited use of the trail integrity statistic $r^{2}$ derived recently, ${ }^{12}$ and in order better to understand how different statistics perform in assessing trail pheromone disruption, it was decided to compare it with the mean distance from the trail for 


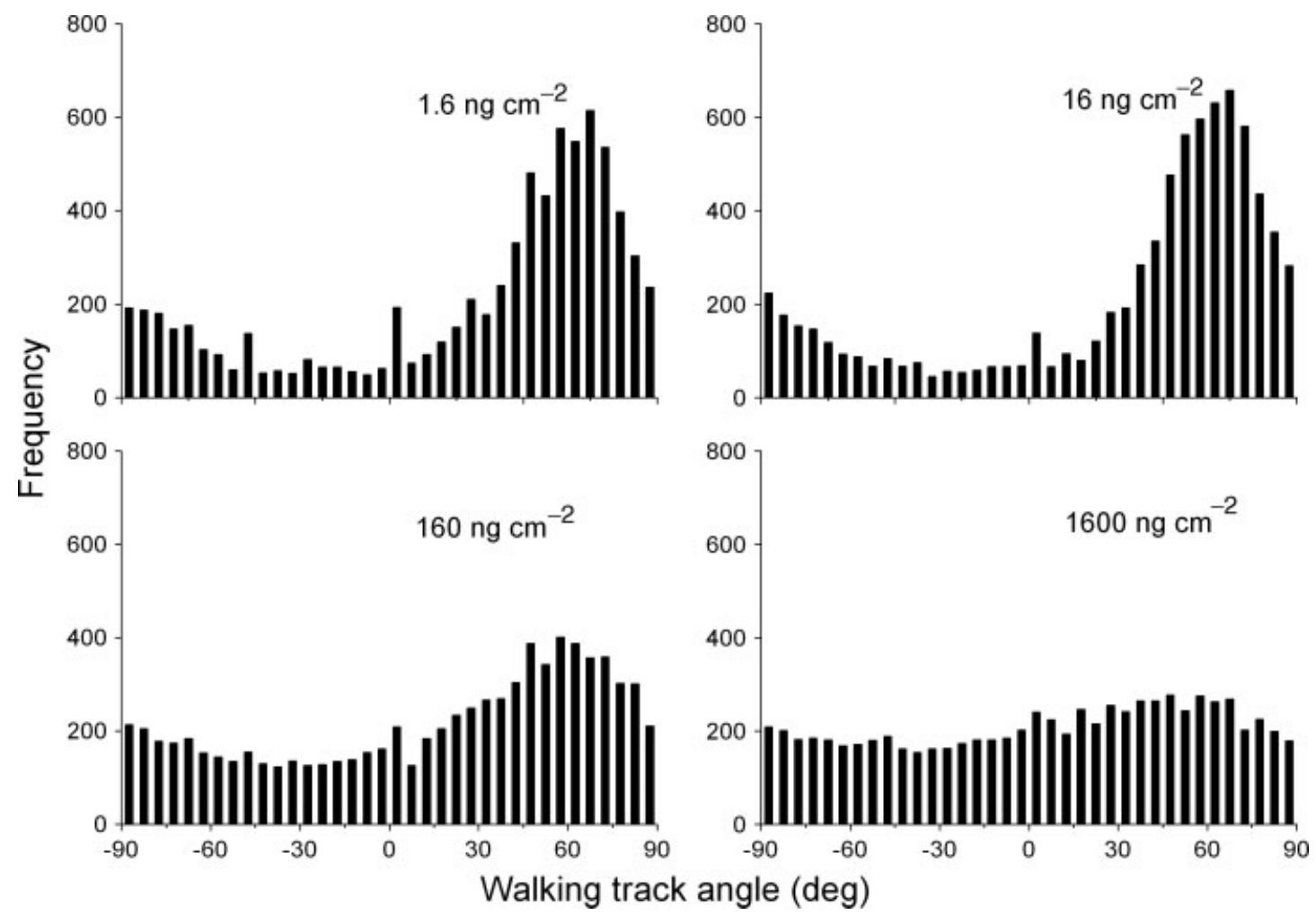

Figure 4. Walking track angles $(\theta)$ of the red imported fire ant, Solenopsis invicta, after exposure to aerosol spray of the trail pheromone $Z, E-\alpha$-farnesene at four concentrations, showing a loss of the peak that occurs at the angle of the trail $\left(63^{\circ}\right)$ above $160 \mathrm{ng} \mathrm{cm}^{-2}$.

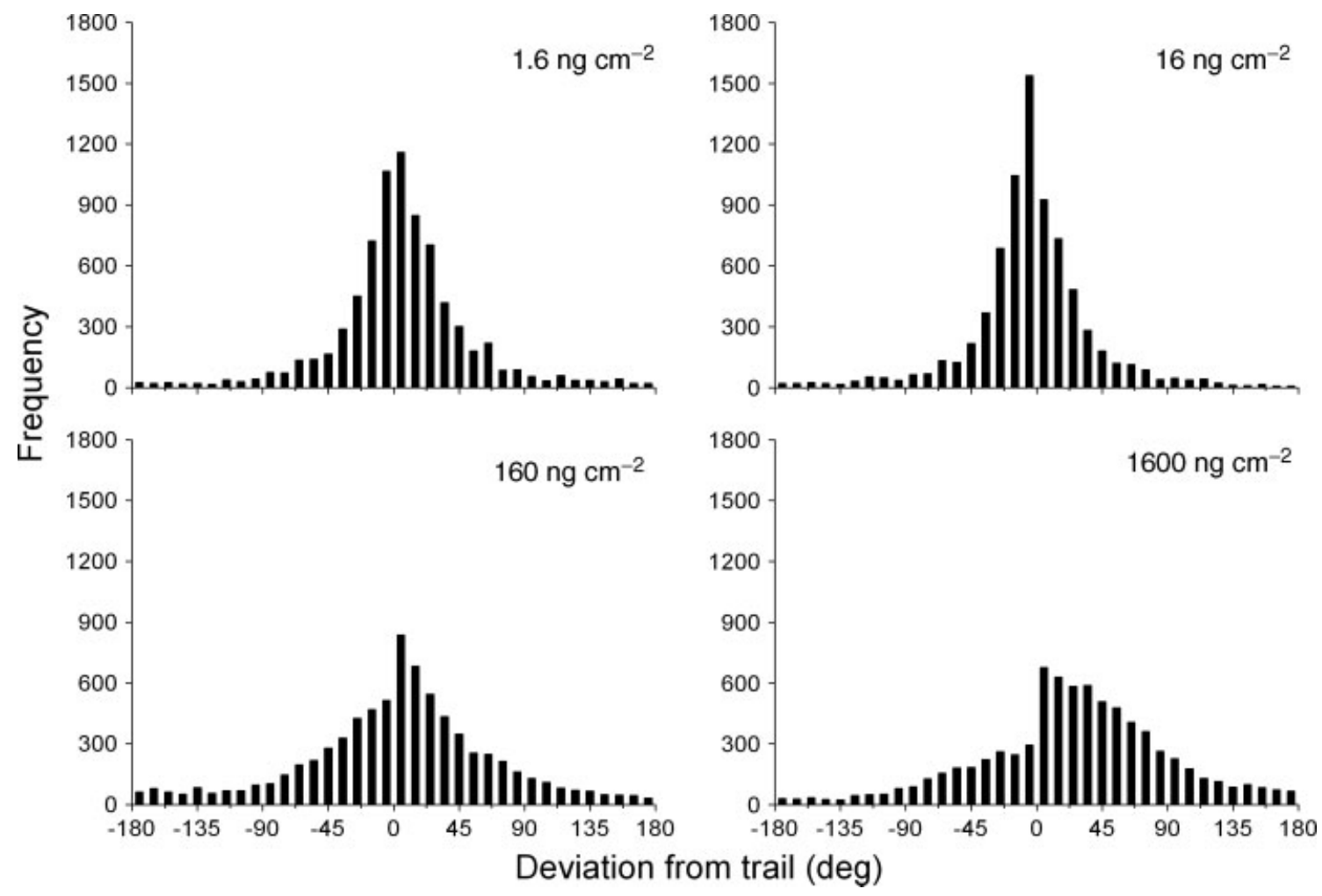

Figure 5. Deviation from the trail (deg) after exposure to aerosol application of $Z, E-\alpha$-farnesene at four concentrations, showing an increase in magnitude of the angle from the trail at $\geq 160 \mathrm{ng} \mathrm{cm}^{-2}$. An excess of positive angles at $1600 \mathrm{ng} \mathrm{cm}^{-2}$ was due to a larger number of ants downwind of the trail. 


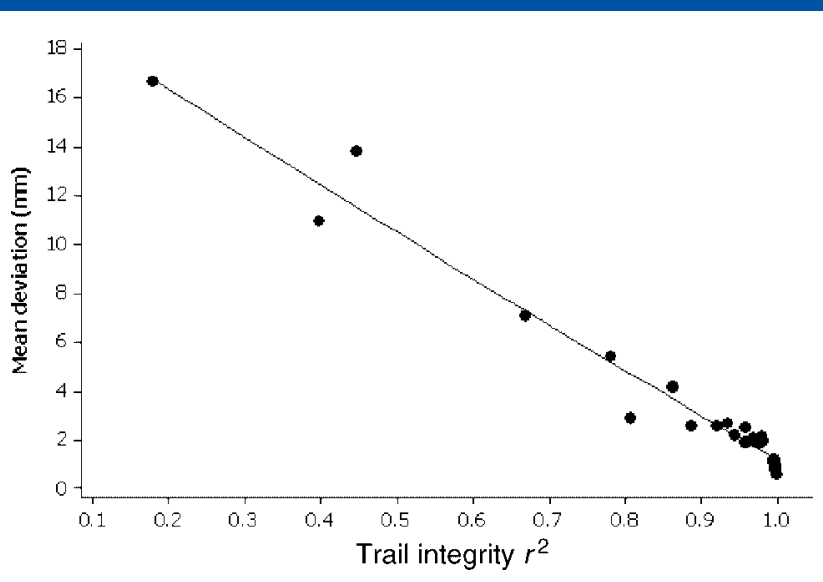

Figure 6. Relationship between trail integrity $r^{2}$ and mean deviation in the red imported fire ant, Solenopsis invicta.

each treatment. Suspected limitations of the $r^{2}$ statistic arose because it is dependent on initial trail angle and the regression component is likely to fit a line of best fit in a different location for each analysis, with line of best fit likely deviating further from the actual trail when trailing deviates significantly from the trail (e.g. when trail disruption occurs). The mean distance from the trail is independent of trail angle and ant trailing owing to each point being compared with the position of the trail that was laid rather than a line of best fit through $x, y$ coordinates. Because of this, the mean distance statistic could be more appropriate for comparisons with other trials. The two limitations of the mean distance statistic over the trail integrity statistic include the need to know the position of the trail and the assumption that the trail can be approximated by a line. Because of this, the mean distance statistic cannot be used in situations where a non-linear trail is used, which can occur with natural trails. For this trial, little advantage of the mean distance statistic over the trail integrity $r^{2}$ statistic was found, and plotting the results of both statistics against the other gave a linear relationship $\left(r^{2}=96.7 \%, P<0.001\right)$, which shows that the trail integrity $r^{2}$ statistic stands up well to minor angle deviations (up to $7^{\circ}$ in this trial) and under high levels of trail disruption.

The deviation from the trail (deg) was tested as a new statistic in the hope of developing a standardised trail angle statistic that was an independent alternative to the walking track angle statistic used by Suckling et al. ${ }^{27}$ This new statistic gives a distribution of angles around $0^{\circ}$ compared with the walking track angle, which gives a distribution centred around the trail angle and so may be affected by large deviations in trail angle (Figs 3 and 4). The new statistic has the same limitations as the mean distance statistic, with the position of the trail required and the requirement of a linear trail that can be approximated by a line. Again, little advantage of the deviation from trail statistic over the walking track angle statistic was found, although it may be more useful where significant deviation in trail angle between treatments occurs. Another difference in the results of the two statistics is in the range of possible angles. The walking track angle equation uses the inverse sine function and so has a range of $-90^{\circ}$ to $+90^{\circ}$, whereas the deviation from the trail equation uses the inverse cosine function and so has an increased range of -180 to $+180^{\circ}$.

It was demonstrated by Hangartner ${ }^{33}$ that worker ants of Lasius fuliginosus orient along odour trails by detecting concentration gradients as they pass in and out of the active vapour space in a zig-zag fashion. Worker ants of Solenopsis invicta likely orient in the same manner by comparing sensory inputs between left and right antennae as they pass across the trail into clean air and back across the odour trail. This would suggest that, during trailing, a distribution of angles centred on the trail would occur, with equal numbers of angle observations on both sides of the trail. This distribution would decline as trail following decreased, such as during trail pheromone disruption, as the zig-zag behaviour back and forth across the trail would be reduced. There was a clear peak in the distribution of angles around the trail angle (63 ) (Fig. 3), which decreased to a nearly flat distribution when the ants were exposed to the highest concentration of $Z, E-\alpha$-farnesene. Another statistic (Fig. 4) showed the deviation from the trail with a peak of angles centred around $0^{\circ}$ at low doses of $Z, E-\alpha$-farnesene supplied by the aerosol spray, with this peak flattening at higher doses as trailing became disrupted. At $1600 \mathrm{ng} \mathrm{cm}^{-2}$ the distribution of angles is skewed to the right, with more ants trailing above the trail, and so the zigzag behaviour across the trail is lost. However, there was a peak in angles around $0^{\circ}$ even at $1600 \mathrm{ng} \mathrm{cm}^{-2}$, and this was probably due to ants entering the frame from the bottom right via a wire bridge in the direction of the trail and so being predisposed to continue in this direction.

While it seems probable that the high dose required for trail formation was due to low purity, i.e. pheromone purity might affect the preferred trail concentration, this has not been specifically tested. It also seems likely that a higher starting concentration on the trail will require a larger dose for disruption. In Argentine ant, Linepithema humile, ${ }^{26}$ a 100 -fold increase in trail pheromone concentration was required for disruption when the trail formation concentration was 100-fold higher.

Aerosol delivery of pheromones has been examined for disruption of a number of moth species and offers the advantage that the frequency of delivery can be set to match the target. For example, MafraNeto and Baker ${ }^{21}$ achieved disruption of almond moth, Cadra cautella, in rooms using an aerosol system. Shorey and Gerber ${ }^{18,20}$ reported promising results with aerosol units in orchards in California. The effectiveness and plume structure generated by aerosols in orchards were demonstrated using a field electroantennogram apparatus and inhibition of catch of lightbrown apple moth, Epiphyas postvittana. ${ }^{22}$ Aerosols are considered to be effective and are widely used for mating disruption of naval orangeworm, Amyelois transitella, in California. ${ }^{34}$ While it is not precisely known how long a single puff will last, commercial aerosol pheromone delivery systems typically puff every few minutes during the period of activity of the target insects, and this could be set to match the requirements for ants in the same way, and offer longer-term control. Aerosol cans placed in the field could be deployed to keep areas free of surface foraging, in the same way that this technology is used in orchards. In fact, Solenopsis and other ants can also be problematical in orchards, ${ }^{35}$ which is one possible area of application because this technology is already in use. It is likely that the containment of $Z, E-\alpha$-farnesene in aerosol cans would increase its stability by removing light and oxygen, but the extent of this benefit would need to be examined. It may also be necessary to use a less volatile solvent to deliver the pheromone to ground level.

There are still questions concerning pheromone purity, off-ratio blends, additional compounds, compound stability, cost and the $Z, E-\alpha$-farnesene concentration of natural trails that impact upon the feasibility of this novel control method. However, the capability of aerosols to disrupt fire ant trails has been clearly demonstrated. The most important hindrance to further development and commercialisation is the lack of a commercial supplier. Besides 
synthesis, the $Z, E-\alpha$-farnesene could possibly be generated from genetically modified bacterial sources, as the biosynthetic pathway has been identified. ${ }^{36}$ Synthesis from $(E)$-nerolidol is also possible. Alternatively, it may be possible to develop pheromone mimics ${ }^{37,38}$ that would bind with odourant receptors effectively to jam the communication channels and produce a longer lasting effect to combat rapid physiological recovery by the ants.

\section{ACKNOWLEDGEMENTS}

Thanks to USDA Agricultural Research Service (Gainesville) for supporting this work, which was also funded by the New Zealand Ministry for Science and Innovation ('Better Border Biosecurity', www.b3nz.org). Thanks also to Warrick J Allen and Andrew Twidle for solvent extraction of the apples, and to Michele Hosack for processing samples used in estimating release rates. The authors are also grateful to Dr Alisdair Noble for statistical advice, and to Tom Sullivan for building the solenoid timer.

\section{REFERENCES}

1 Allen CR, Epperson DM and Garmestani AS, Red imported fire ant impacts on wildlife: a decade of research. Am Midland Nat 152:88-103 (2004).

2 Eubanks MD, Estimates of the direct and indirect effects of red imported fire ants on biological control in field crops. Biol Control 21:35-43 (2001).

3 Rhoades RB, Stafford CT and James FK, Jr, Survey of fatal anaphylactic reactions to imported fire ant stings. J Allergy Clin Immunol 84:159-162 (1989).

4 El-Sayed AM, The Pherobase: Database of Pheromones and Semiochemicals. [Online]. Available: www.pherobase.com Accessed [15 June 2012].

5 Tumlinson JH, Silverstein RM, Moser JC, Brownlee RG and Ruth JM, Identification of the trail pheromone of a leaf-cutting ant, Atta texana. Nature (Lond) 234:348-349 (1971).

6 Rust MK, Reierson DA and Klotz JH, Delayed toxicity as a critical factor in the efficacy of aqueous baits for controlling Argentine ants (Hymenoptera: Formicidae). J Econ Entomol 97:1017-1024 (2004).

7 Vander Meer RK, Potential role of pheromones in fire ant control, in Pest Management in the Subtropics: Integrated Pest Management - a Florida Perspective, ed. by Rosen D, Bennet FD and Capinera JL. Intercept Ltd, Andover, Hants, UK, pp. 223-232 (1996).

8 Tatsuki S, Terayama M, Tanaka Yand Fukumoto T, Behavior-disrupting agent and behavior-disrupting method of Argentine ant. US Patent 2005/0209344 A1 (2005).

9 Sunamura E, Suzuki S, Nishisue K, Sakamoto H, Otsuka M, Utsumi Y, et al, Combined use of a synthetic trail pheromone and insecticidal bait provides effective control of an invasive ant. Pest Manag Sci 67:1230-6 (2011).

10 Tanaka Y, Nishisue K, Sunamura E, Suzuki S, Sakamoto H, Fukumoto T, et al, Trail-following disruption in the invasive Argentine ant with a synthetic trail pheromone component (Z)-9-hexadecenal. Sociobiology 54:139-152 (2009)

11 Nishisue K, Sunamura E, Tanaka Y, Sakamoto H, Suzuki S, Fukumoto T, et al, Long-term field trial to control the invasive Argentine Ant (Hymenoptera: Formicidae) with synthetic trail pheromone. J Econ Entomol 103:1784-1789 (2010).

12 Suckling DM, Peck RW, Manning LM, Stringer LD, Cappadonna J and El-Sayed AM, Pheromone disruption of Argentine ant trail integrity. $J$ Chem Ecol 34:1602-1609 (2008).

13 Suckling DM, Peck RW, Stringer LD, SnookK and Banko PC, Trail pheromone disruption of Argentine ant trail formation and foraging. J Chem Ecol 36:122-128 (2010).

14 Wilson EO, Source and possible nature of the odor trail of fire ants. Science 129:643-644 (1959).

15 Wilson EO, Chemical communication among workers of the fire ant Solenopsis saevissima (Fr. Smith). 1. The organization of massforaging. Anim Behav 10:134-147 (1962).
16 Vander Meer RK, Alvarez F and Lofgren CS, Isolation of the trail recruitment pheromone of Solenopsis invicta. J Chem Ecol 14:825-838 (1988).

17 Suckling DM, Stringer LD, Bunn B, El-Sayed AM and Vander Meer RK, Trail pheromone disruption of red imported fire ant. $J$ Chem Ecol 36:744-750 (2010).

18 Shorey $\mathrm{HH}$ and Gerber RG, Use of puffers for disruption of sex pheromone communication of codling moths (Lepidoptera: Tortricidae) in walnut orchards. Environ Entomol 25:1398-1400 (1996).

19 Shorey HH and Gerber RG, Disruption of pheromone communication through the use of puffers for control of beet armyworm (Lepidoptera: Noctuidae) in tomatoes. Environ Entomol 25:1401-1405 (1996)

20 Shorey HH and Gerber RG, Use of puffers for disruption of sex pheromone communication among navel orangeworm moths (Lepidoptera: Pyralidae) in almonds, pistachios, and walnuts. Environ Entomol 25:1154-1157 (1996).

21 MafraNeto A and Baker TC, Timed, metered sprays of pheromone disrupt mating of Cadra cautella (Lepidoptera: Pyralidae). J Agric Entomol 13:149-168 (1996).

22 Suckling DM, Daly JM, Chen X and Karg G, Field electroantennogram and trap assessments of aerosol pheromone dispensers for disrupting mating in Epiphyas postvittana. Pest Manag Sci 63:202-209 (2007).

23 Banks WA, Lofgren CS, Jouvenaz DP, Stringer CE, Bishop PM, Williams DF, et al, Techniques for collecting, rearing, and handling imported fire ants. USDA/SEA/AATS-S-21, 9 pp. (1981).

24 Murray KE, $\alpha$-Farnesene: isolation from the natural coating of apples. Aust J Chem 22:197-204 (1969).

25 Spicer JA, The oxidation of alpha farnesene. PhD Thesis, Massey University, Palmerston North, New Zealand (1994).

26 Ramaiah P, Pegram JJ and Millar JG, A short synthesis of (3z,6e)-alphafarnesene. J Org Chem 60:6211-6213 (1995).

27 Suckling $D$, Stringer $L$ and Corn J, Argentine ant trail pheromone disruption is mediated by trail concentration. J Chem Ecol 37:1143-1149 (2011).

28 Morgan ED, Keegans SJ, Tits J, Wenseleers T and Billen J, Preferences and differences in the trail pheromone of the leaf-cutting ant Atta sexdens sexdens (Hymenoptera: Formicidae). Eur J Entomol 103:553-558 (2006).

29 Evershed RP, Morgan ED and Cammaerts MC, 3-Ethyl-2,5dimethylpyrazine, the trail pheromone from the venom gland of eight species of Myrmica ants. Insect Biochem 12:383-391 (1982).

30 Vander Meer RK, Semiochemicals and the red imported fire ant (Solenopsis invicta Buren) (Hymenoptera: Formicidae). Fla Entomol 66:139-161 (1983).

31 Linn CE, Campbell MG and Roelofs WL, Pheromone components and active spaces - what do moths smell and where do they smell it? Science 237:650-652 (1987).

32 Minks AK and Cardé RT, Disruption of pheromone communication in moths: is the natural blend really most efficacious? Entomol Exp Appl 49:25-36 (1988).

33 Hangartner W, Spezifität und Inaktivierung des Spurpheromons von Lasius fuliginosus Latr. und Orientierung der Arbeiterinnen im Duftfeld. Z Vergleichende Physiol 57:103-136 (1967).

34 Higbee BS and Burks CS, Effects of mating disruption treatments on navel orangeworm (Lepidoptera: Pyralidae) sexual communication and damage in almonds and pistachios. I Econ Entomol 101:1633-1642 (2008).

35 Green SA, Friel EN, Beuning LL and Macrae EA, Plant alpha farnesene synthase and polynucleotides encoding same. US Patent 2005/7309817 (2007).

36 Tollerup KE, Rust MK, Dorschner KW, Phillips PP and Klotz JH, Lowtoxicity baits control ants in citrus orchards and grape vineyards. Calif Agric 58:213-217 (2004).

37 Camps F, Coll J, Fabriàs G, Guerrero A and Riba M, Fluorinated analogs of insect sex pheromones. Cellular Mol Life Sci 40:933-934 (1984).

38 Prestwich GD, Fluorinated sterols, hormones and pheromones: enzyme-targeted disruptants in insects. Pestic Sci 17:430-440 (1986). 